\title{
DISKUSSIE OOR KERK EN KERKVERBAND
}

\section{DR. DIRK FOURIE, BRYANSTON, SKRYWE:}

Baie dankie dat $u$ my vorige brief woordeliks geplaas het. Ter wille van duidelikheid oor verskilpunte, versoek ek vriendelik om 'n woord van repliek te lewer op die standpunte van professore B. Spoelstra en L. Roeleveld, soos gelug in In die Skriflig, Desember 1979,47 en verder.

1 Wat prof. Spoelstra betref, konstateer hy

1.1 dat ons twee "nie heeltemal op dieselfde golflengte ingestel is nie." Inderdaad is dit so en ek meen dat ek weet waarom. S volg met betrekking tot die aard van die kerkverband in hoofsaak die Doleantie-kerkregtelikes Lohman en Rutgers wat geleer het: „Het is zeer onschriftuurlijk, ongereformeerd en onjuist de gezamentlijke kerken eener provincie de provinciale kerk te noemen" (Rechtsbevoegdheid, 62). Aan die ander kant volg ek in hierdie opsig vir Voetius, wat geskryf het: „Die klassikale of sinodale verband is 'n blywende samevoeging van meerdere gemeentes onder ' $n$ bepaalde regering en 'n verband tot onderlinge opbouing en bewaring" (P E $4,119)$. M. Bouwman verklaar dat die terme wat Voetius gebruik, ,wijst beslist in de richting dat hij het geheel der synodaal verbonden kerken opvat als een kerkrechtelijke, corporatieve eenheid, zoals ook de plaatselijke kerk een eenheid is in institutaire zin" (Voetius, 71-72).

Tussen bostaande twee kerkregtelike standpunte bestaan natuurlik 'n yslike prinsipiële verskil, maar ek verstout my om te sê dat ek na 'n studie van ons drie Afrikaanse kerke se kerkordes, bepalinge en besluite tot die slotsom gekom het dat al drie kerke offisieel op die standpunt van Voetius staan: Die kerkverband is 'n kerkregtelike, juridiese eenheid van meerdere gemeentes, met sy eie identiteit en bevoegdhede, en word met die term kerk in die enkelvoud aangedui.

1.2 „Ek meen dat indien Roeleveld vir DF korrek aangehaal het, my opmerking wat DF aanhaal volkome in die kol is."

Op grond van wat $S$ van $R$ verneem het, kry ek die etiket van kollegialis om my nek. Hoorsê-getuienis is natuurlik waardeloos, en om op grond daarvan 'n uitspraak te maak, is nog meer waardeloos; daarom laat ek die betrokke argument daar.

1.3 „Die kollegialisme reken gewoonlik met 'n abstrakte eenheid „kerk" wat in plurale gemeentes sigbaar word. So is daar sê maar een $\mathbf{N}$ G Kerk in en agter die baie N G gemeentes. Hierdie "N G Kerk" is 'n abstraksie of idee N G Kerk (enkelvoud)".

Wie met betrekking tot die kerkverband met fiksies en abstrak. sies wil werk, soos die juris Von Savigny met die regspersoon as sodanig probeer het, beland in 'n doolhof van onwerklikhede. Wie uit N G kringe het al soiets probeer? Die kerkverband (as voorbeeld die N G Kerk in die OVS) is die eienaar van 'n sinodale sentrum; is 'n werkgewer van 'n groot personeel; is ' $n$ kontrak. terende party teenoor die argitek en die boumeester van sy sinodale 
sentrum; die kerkverband dagvaar of kan gedagvaar word-dus, geen fiksies of abstraksies kom na vore nie. Die kerkverband as 'n voortdurende verband van gemeentes staan soos 'n koei voor jou, soos die Nederlanders sou sê.

1.4 „DF se kerkbegrip is vir my onverstaanbaar.... Wat is hierdie begrip "sinodale verband" anders as 'n kollegialistiese oorkoepelende ,kerk"?

Met „sinodale verband" bedoel ek wesenlik wat art. $52 \mathrm{KO}$ van die GKSA bedoel: „Kerklike korrespondensie en samewerking of kontak (met kerke en kerklike instansies) buite die algemene sinodale verband, word in 'n algemene sinode gereël (kyk bladsy 81)”. Art. 51 leer: „Die algemene sinode is 'n vergadering van al die nasionale sinodes...." Dus, algemene sinodale verband beteken hierdie verband van die kerke wat die Algemene Sinode daargestel het en wat daarheen afgevaardiges stuur. Soos Voetius sê, is 'n sinode 'n conventus ecclesiarum, d.w.s. 'n samekoms van kerke of gemeentes.

Indien hierdie konstruksie kollegialisties is, is Voetius en al drie ons Afrikaanse kerke kollegialiste.

1.5 „Die gestruktureerde groepering (genootskap?) is uitgangspunt en benodig 'n orgaan. Sy orgaan is elke keer ook weer 'n kollegium, 'n vergadering. DF fundeer die kerkregering dus nie in die presbiterepiskopos of plurale ouderlinge van die Skrif nie, maar in die orgaan as kerkraad, ring of sinode (ook 'n collegium)." Hierdie standpunt, verklaar S, bewys dat DF nie met die „gesekulariseerde genootskaplike kerkbegrip uit die 18de eeu wat die howe toepas" gebreek het nie. „In die kollegialisme ontleen die orgaan sy bevoegdheid aan die struktuur wat hy verteenwoordig...."

Buig of bars, Fourie is 'n kollegialis en hy moet een bly! Kom ons kyk of ons mekaar kan verstaan.

1 Christus het die dienswerk in Sy sigbare, institutêre kerk aan ampsdraers opgedra.

2 Hy regeer Sy kerk deur ampsdraers in vergadering. In die kerkraad dien hulle kragtens hul ampsbevestiging, in die meerdere vergaderinge ingevolge hul afvaardiging.

3 Sodanige kerkvergaderinge het ,elkeen na sy eie aard, 'n kerklike gesag deur Christus aan hulle verleen" (NGK KO art. 20.1: GKSA KO art. 36).

4 'n Kerkvergadering, bv. 'n kerkraad, ,verteenwoordig die kerk” (GKSA KO art. 11). Dit wil sê, handel die kerkraad, beteken dit dat die gemeente gehandel het. Die kerkraad is dus primêr die gemeente se orgaan of sy verteenwoordiger.

5 Laat ons nie in hierdie opsig bontpraat nie. Vergelyk die Handleiding by die Kerkorde van die GKSA op die volgende bladsye: 186: „Volgens so 'n opvatting regeer vergaderinge (kolleges) en nie ouderlinge (presbiters) nie. Daarmee word die weg van die kollegialisme betree en die suiwer presbiteriale spoor verlaat."

217: „In die gereformeerde kerkreg word hierdie beginsel nie erken 
nie. Nie persone nie, maar kerklike vergaderinge oefen die regeermag uit. Nie persone nie, maar die besluite van die betrokke kerklike vergadering regeer."

Nouja? Die korrekte is natuurlik: Christus regeer Sy kerk, plaaslik sowel as in sy verband, deur ampsdraers in vergadering; dit is die ons in die ons en die Heilige Gees het besluit.... Dit is so in die geval van 'n kerkraad as ' $n$ permanente kollegie en 'n meerdere vergadering as 'n tydelike kollegie.

2 Wat prof. Roeleveld betref, is ek jammer dat hy nie kans sien om te antwoord op my - ek meen redelike en billike vrae - nie. Trouens, as juris beveel $\mathrm{R}$ aan dat die Sinode van die GKSA (bedoel DF NGKSA?) hoofstuk 5 van die Kerkorde moet heroorweeg „ook vanuit die geestelike karakter van die gereformeerde kerkverband", wat dit ook al mag beteken.

Nou meen ek, is $R$ dit redelikerwys aan sy eie Kerk verskuldig om juridiese kommentaar te lewer op die volgende:

1 Maak hoofstuk 5 van die kerkverband in die praktyk 'n regspersoon, ja of nee?

2 Presies in watter opsigte moet die bepalinge van hoofstuk 5 heroorweeg word? Waarom?

3 Wat is die regsgevolge van sodanige moontlike wysigings veral in die geval van krisis-situasies soos kerkskeurings?

4 Kommentaar op die besluit van die Nederlandse Generale Sinode van Middelburg in 1933, wat lui: „De kerken, die in classes, particuliere synoden en generale synode samenkomen, vormen tezamen even zoovele vermogensrechtelijke eenheden ten aanzien van de stoffelijke aangelegenheden".... en die toets-saak wat daarna by die hof aanhangig gemaak is (sien Nauta: Verklaring, 340 en verder). 5 Gemotiveerde kommentaar op die korrektheid van die beslissing in die gewysigde Venter $v$ Gereformeerde Kerkeraad, Bethulie, 1879, OVS, 4.

Eers wanneer die geagte Sinode volledig ingelig is, kan hy die konsekwensies van voorstelle wat voorgebring word, na behore peil.

\section{PROF. B. SPOELSTRA ANTWOORD:}

Dr. Dirk Fourie betrek die kollegialisme wat ek in sy standpunte lees, as 'n etiket op sy persoon en neem aanstoot. Uiteraard neem kollegialisme baie vorme aan. $\mathrm{Ek}$ is selfs soms slagoffer daarvan. Die volgende kenmerke maak m.i. o.a. 'n standpunt (nie 'n persoon nie) kollegialisties: wanneer 'n kerkvergadering die vertrekpunt en basis vir kerkregering vorm; wanneer die kerkregtelike situasie nie uit die Skrif nie maar uit Kerkordes, konstitusies en sinodale besluite opgemaak of uit algemene regsbegrippe soos „korporasies" afgelei word en wanneer canonici aangehaal word om op hulle uitsprake 'n beginsel te fundeer; wanneer vergaderinge van ,ampsdraers" (nie eers "ouderlinge" nie) van kerkraad af op een lyn vir 'n „,kerkverband" deurgetrek word wat op sy beurt ringe en sinodes as sy organe het. Die ,kerkverband" is m.i. maar net 'n „kerkgenontskap".

Daarteonoor aanvaar ek as Bybels en Reformatories volgens 
die Ned. Geloofsbelydenis art. 27-32 dat die kerk 'n eenheid van gelowiges is; dat Christus die enigste hoof van sy kerk is en dat sy gesag deur alle kerklike dienaars bedien word en kerkvergaderinge daarom dieselfde gesag het (KO GKSA art. 36); dat Christus ouderlinge roep deur wie Hy sy Woord regerend laat bedien; dat die ouderlinge kragtens roeping en nie kragtens hulle aanwesigheid ,in vergadering" (soos DF stel nie) regeer nie (vgl. eerste vraag van die bevestigingsformulier); dat die kerkraad eers apostereories met die oog op kerklike regspraak in tuggevalle (sencura morum) in die prentjie kom (soos dit in afdeling 2 van die Dordtse $\mathrm{KO}$ na die dienste aangedui word en Calvyn in sy Institusie, Boek IV met die onderskeiding van die drieërlei kerklike magte aandui). Kerke kom saam in klassis (sinode) met die oog daarop om mekaar in kerkregering te help en nie om 'n „,kerkverband" naas die plaaslike kerke te vorm of beoefen nie. Die saamgaan van die kerke op grond van kerkverband vir kerkregering geskied deur middel van ' $n$ Kerkorde wat met mekaar vrywillig aangegaan word maar nie vryblywend nie. Die handelende subjek in die klassis (sinode) wat art. 41 DKO defineer as bestaande uit plurale kerke, bly daarom die plurale kerke en nie 'n ,kerkverband" nie. Hulle handel wel in kerkverband van geloofs- en kerkordelike gemeenskap. Met die Kerkorde wat aangegaan is om 'n klassis of sinode moontlik te maak, het nie 'n algemene „kerk" of „kerkverband” ontstaan nie. Indien DF dit wil beweer, noem ek sy opvatting kollegialisties.

DF het in Die Kerkbode ( 20 en 27 Feb. en 5.3.80) ook na verskillende uitsprake van my verwys. Hy haal my daar oor „kerkverband" aan uit die „Handleiding by die KO van die GKSA", 1966. Sedert 1965 het ek oortuig geraak dat „kerkverband” verkeerdelik uit die Nederlandse literatuur by ons as 'n substansiële of soortnaam in omloop gekom het. Kerkverband druk in wese 'n relasie uit soos die begrippe „gesinsverband" en ,volksverband” ook doen. 'n Mens kan nooit 'n gesin en gesinsverband langs mekaar stel soos DF met kerk en kerkverband doen nie. Stel u voor dat 'n gesin en gesinsverband elk eie en aparte „organe" het!

DF het nooit presies gesê wat hy onder „kerkverband" verstaan nie. Bedoel hy nie met „kerkverband" maar „kerk in die geheel" nie? Is die universele gemeente van Christus in die ,sinode" sigbaar soos in die plaaslike gemeente? Indien wel hoe kan die sinode dan „orgaan" van die „kerkverband" wees soos die kerkraad dit van die gemeente is? Dit lyk asof dit al illustreer waarmee hy in I.3 van sy skrywe probleme het, nl. dat NG Kerk of ,kerkverband" 'n abstraksie of idee word. Indien hy sinode met kerkraad vergelyk, wat vergelyk hy dan konkreet agter die sinode met die konkrete gemeente? Ek is nie bereid om 'n vergadering van "ampsdraers" en net mans in 'n sinode as beeld van die universele kerk te sien nie. Calvyn wys in sy Institusie ook uitdruklik die Roomse opvatting dat die konsilie beeld van die kerk is af (IV, ix, 1.3; viii, 10 ens.).

Calvyn se kerkbegrip het in hoofsaak die Ned. Geloofsbelydenis Art 27-32 gevorm. Daarvolgens openbaar nie uitwendige organisasie en instituut nie, maar geloof en die relasie tot Christus die 
gemeenskap wat ons kerk noem. Ek kry ook nie die indruk dat DF kennis geneem het van bv. prof. W. J. Snyman se studies oor die gebruik van die woord kerk in die NT nie. Waar ek probeer om die Bybelse kerkbegrip te hanteer, verwerp ek die stelling dat ek met „Doleansie"-kerkreg werk. Ek het immers in artikels al aangetoon dat die Doleansie-kerkregtelikes die dualistiese kerkbegrip van „plaaslike kerk” en ,algemene kerk” tog weer met hulle newestelling kerk en kerkverband opgeneem het. Ek het daarin ook beweer dat M. Bouwman Voetius deur 'n kollegialistiese bril gelees het (vgl. o.a. In die Skriflig 1967, $\mathrm{nr} .3$ ). Ek is egter baie seker dat al slaag ek self nie om die kerkbegrip altyd volgens die Belydenis te hanteer nie, ek dit nie aan die Romeins-Hollandse reg ontleen nie.

Vervolgens sou ek ook net wil aanstip dat die selfstandige kerke in Nederland wat uit die Reformasie ontstaan en tot en met Emden 1571 soos die stadskerk van Geneve sonder ,kerkverband" bestaan, bewys duidelik dat samekomste van kerke in sinodes nie plaasvind om kerke of "kerkverbande" te maak nie. 'n Sinode is 'n samekoms van kerke wat 'n geestelike eenheid het met die oog op kerkregering. DF se konstruksie van 'n kerkverband met 'n sinodeorgaan naas die kerk met 'n kerkraad-orgaan is kollegialisties, of hy van die woord hou of nie.

\section{Enkele opmerkings volgens $D F$ se nommering:}

Ad 1.2: DF suggereer dat ek hom op „,hoorsê"-getuienis aanspreek. Ek het egter sy eie skrywes gebruik en daarom bly hy in gebreke om aan te voer dat ek hom iewers verkeerd aangehaal het.

Ad 1.3: DF het klaarblyklik my verwysing na die abstrakte kerk. begrip misverstaan. Tydens die Hervorming was daar twee konkrete kerkbegrippe, empiries aanwysbaar, nl. die priesterinstituut van Rome met sy kanonieke reg en daarteenoor plurale reformatoriese stadskerke en/of Lutherse landskerke. Die kerke is regeer deur priesters en biskoppe aan die een kant, biskoppe, pfarrers en/of ouderlinge aan die ander kant. Gedurende die 18de eeu ontwikkel die Rasionalisme egter 'n nuwe ,idee" met bv. Rousseau se Contrat Social, waarin die ,idee" staat of kerk na vore tree. Dit word volgens die teorieë van delegasie en representasie as regsbegrippe gekonstrueer. Hierdie eenheid, genootskap of kerk is 'n rasionele abstraksie wat op sterkte van konstitusies en wetlike omlyninge gedefineer word, maar wat nie konkreet soos die gemeente bestaan en opereer nie. So beskou ek dat daar 'n ,idee" bestaan dat iemand bv. aan die NGKSA behoort en dat daardie NGKSA sigbaar en konkreet word in sy tak, die gemeente. Wil DF sê dat die NGKSA presies saamval met en kongruent is aan die persone wat optree as „eienaars” van die kerkgeboue, wat werknemers in diens neem of wat die kontrak met 'n argitek onderteken? Indien ek volgens art. 27-28 NGb die kerk as mense konkreet kan aandui, kan ek nie anders as om die begrip NGKSA as 'n wetlike omlynde korporasie, maar nietemin as 'n abstrakte kerkbegrip in terme van wat ' $n$ kerk volgens die Skrif is, te verstaan nie. 
Ad 1.4: Ek het deurgaans met DF se kerkbegrip en metode probleme. Hy gebruik bv. art. 51 van die KO GKSA wat 'n algemene sinode defineer as saamgestel uit (NB nie ,deur" nie) plurale sinodes. DF maak van die omskryfde meervoud egter in sy redenasie (d.m.v. rasionele abstraksie) summier 'n enkelvoud wat hy ,verband" noem. Bedoel hy kollegium, genootskap? Hierdie enkelvoudige ,verband" stuur volgens DF afgevaardigdes na ,die" sinode. Hierdie logiese spronge en oorgange om in 'n skema te pas, maak dit moeilik. Hy verswyg daarom by Voetius dat 'n konvent of sinode bestaan ,ex delegatis plurium ecclessiarum", wat Voetius self so verstaan dat die plurale kerke daar aanwesig is. Dit is iets anders as wanneer kerke slegs die lede van 'n sinode aanwys. Voetius se begrip conventus (saamkoms) verskil van DF se begrip ,korporasie" waarop hy in Die Kerkbode neerkom. Eersgenoemde begrip is minstens dinamies en erken die plurale subjekte wat saamkom; laasgenoemde begrip is staties en absorbeer die veelheid tot sy eie "lede" en die geheel is meer as die dele. Sinodale Korporasie pas inderdaad nie op die reformatoriese begrip vir samekoms van meer kerke nie.

Ad 1.5: DF sê eintlik presies wat hy my kwalik neem dat ek hom dit ten laste lê. Hy sê die ,ampsdraer" dra gesag kragtens sy "ampsbevestiging" en regeer ",in vergadering". Hy fundeer die "amp" volledig in die kollegium. Die vergadering het daartoe "kerklike gesag”, waartoe hy verkeerdelik na art. $36 \mathrm{KO}$ verwys. Die artikel praat nie oor die kerkregering in die gemeente nie. Wanneer van die gesag van Christus en daarmee saam sommer ongekwalifiseerd van die uitoefening van "kerklike mag" gepraat word, sou ek graag wil weet waarin dié opvatting van die Roomse verskil. Die hele beginsel van geestelike regering en bedienende mag wat gebonde bly aan en begrens word deur die Woord, laat DF buite rekening. Hy fundeer die kerklike mag in kerklike strukture.

Die stelling sub nr. 4 dat die kerkraad (LW) „primêr” die gemeente se orgaan is, laat my vra of Christus nie „primêr" ouderlinge (en daarom nie „,ampsdraers" van 'n liggaam nie) as sy organe tot diens roep nie? Val die geestelike en wesenlike regering van die kerk (bv. tugoefening) op dieselfde vlak van regering as bv. die onderhoud van predikant? Ek dink dat ons totaal vasloop wanneer ons ongenuanseerd iets wat m.b.t. die onderhoud van 'n predikant kontraktueel waar is tot 'n stelreël wil verhef waaruit ons algemene regsbeginsels wil aflei.

PROF. L. ROELEVELD verkies om nie op DF se skrywe te antwoord nie, maar in die volgende uitgawe sal DV van hom 'n artikel verskyn: „Die Gereformeerde Kerkverband as Societas van plaaslike Gemeentes". 